\title{
Screening for Bovine Trichomonosis at Organized Farms using Inpouch TF Kit
}

\author{
K. V. Ananthakumar ${ }^{1 *}$, K. Sathish ${ }^{1}$, G. Dhinakar Raj ${ }^{1}$, M. $\operatorname{Raman}^{1}$, \\ Amir Kanji ${ }^{2}$ and P. Azhahianambi ${ }^{1}$ \\ ${ }^{I}$ Department of Translational Research Platform for Veterinary Biological (TRPVB) \\ ${ }^{2}$ Department of BIOMED diagnostics, USA \\ *Corresponding author
}

\section{A B S T R A C T}

\begin{tabular}{|l|}
\hline Ke y w or d s \\
Tritrichomonas \\
foetus, Inpouch TF \\
kit, Abortion
\end{tabular}

Tritrichomonas foetus causes Trichomonosis in cattle which cause early abortion in cows. To study the prevalence of bovine trichomonosis, we have optimized OIE recommended gold standard method using Biomed's Inpouch TF kit. Tritrichomonas foetus (Riedmuller) Wenrich and Emerson $\left(\mathrm{ATCC}^{\circledR} 30003^{\mathrm{TM}}\right.$ ), strain BP-4: Beltsville was purchased from American Type Culture Collection (ATCC) and growth parameters were studied under our laboratory conditions using Biomed's Inpouch TF kit and Inhouse prepared media. We have screened a total of 444 bulls from various Government organized semen production stations for the presence of Tritrichomonas foetus. None of the bulls were found positive of Tritrichomonas foetus.

\section{Introduction}

Tritrichomonas foetus is one of the protozoan parasites of veterinary importance placed under the genus Tritrichomonas. Tritrichomonas foetus causes trichomonosis which leads to early abortion in bovine and buffalo population (10). Considerable economic losses like early embryonic mortality and milk production are associated with the disease $(2,5,9)$. India has 109.3 million buffalo and 304 million bovine populations and it comprises approximately 56 percentage of the total world population (1). Livestock plays a major component of India's economic growth in terms of its rural income, employment and export revenue. Brucella spp., Campylobacter spp., Leptospira spp. Listeria spp., Tritrichomonas spp., Salmonella spp., Chlamydophila spp. and Mycoplasma spp., are the major pathogens that cause abortion and reproductive losses in cattle and buffalo $(4,10)$ and use of infected community bulls was the major reason for the spread of this parasite. Bulls are the carriers of T. fetus and spread it to cows during mating. Infected 
cows can also transmit the parasite to the uninfected bulls while mating (3). The prevalence of bovine trichomonosis is not well studied in India but it is believed that around $3-4 \%$ of abortions are due to T. foetus. (6). Tritrichomonas fetus parasite resides in the urogenital tract of cattle and causes bovine trichomonosis and there is no approved treatment for bovine trichomonosis (12). Trich Guard, a killed vaccine against $T$. fetus, is the only vaccine licensed to reduce the shedding of T.foetus organisms, and thus helps protect against the spread of trichomonosis in cattle. However, managing the risk factors through bio security is more effective than vaccination.

In the present study, the OIE approved methodology to identify the T.foetus was used to screen 444 bulls from various Government of India authorized semen production stations. Our results indicate that bulls from the organized semen production stations were negative for bovine trichomonosis.

\section{Materials and Methods}

Tritrichomonas foetus (Riedmuller) Wenrich and Emerson $\left(\mathrm{ATCC}^{\circledR} 30003^{\mathrm{TM}}\right.$ ), strain BP-4: Beltsville was procured from American Type Culture Collection and Cryo-preserved as per manufacturer's Instructions.TF-Inpouch Kit was procured from Bio Med, USA.

\section{Reviving the Tritrichomonas foetus}

The organisms were thawed by placing frozen ampoule in $35-37^{\circ} \mathrm{C}$ water bath for $2-3$ minutes. Immediately after thawing, the organism was aseptically transferred into screw-capped test tube $\left[\begin{array}{lll}16 & \mathrm{x} & 125 \mathrm{~mm}\end{array}\right]$ containing $9 \mathrm{ml}$ of Diamonds modified media

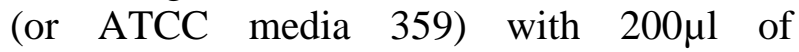
inactivated horse serum and incubated at 35$37^{\circ} \mathrm{C}$ till the organism grows. The organism were also inoculated into InPouch TF kit (BIOMED, USA). Media components utilization and media preparation was followed as per manufacturer's instructions.

\section{Maintenance}

\section{Cell count}

Performing viable count of the highly motile Tritrichomonas foetus organism is highly challenging and therefore, a simple method was developed to count the organism under compound microscope. Normal PBS (pH 8.0) at slightly alkaline condition was mixed with media containing organism in different ratio's $(\mathrm{V} / \mathrm{V})$ viz. $25 \%, 50 \%, 75 \%$ and observed under microscope.

\section{Growth curve experiment}

To determine the growth kinetics of T.foetus, a total of $3 \times 10^{6}$ cells (in $400 \mu$ l) were inoculated into sterile $15 \mathrm{ml}$ falcon tube containing $9.0 \mathrm{ml}$ of TF (ATCC) media with $200 \mu 1$ of horse serum and incubated at $35^{\circ} \mathrm{C}$.Cell growth was monitored based on two parameters Cell count under compound microscope and $\mathrm{OD}_{600}$ of the media, at regular intervals $(18,24,40,48 \mathrm{hrs}$ after inoculation). The experiment was repeated for 3 times and the mean was calculated.

\section{Analytical sensitivity of Tritrichomonas foetus culture method}

A total of $3 \times 10^{6}$ cells were inoculated into $9 \mathrm{ml}$ of TF (ATCC) media and serially diluted till $10^{-11}$ dilutions. Growth of the organism was monitored for 6 days by checking the culture $\mathrm{OD}_{600}$ and identification of the Organism under microscope. The experiment was repeated for three times.

\section{Analytical sensitivity of PCR}

The organism was serially diluted from $10^{6}$ cells to $10^{1}$ cells and the total genomic DNA 
was extracted from each dilution. A polymerase chain reaction was performed with 3 sets of TF specific primers. Published oligonucleotide primers were used to amplify 208-bp fragment internal transcribed spacer region and 342-bp fragment of 5.8s ribosomal DNA of $T$. foetus (rDNAs) $(9,11)$

\section{Screening the bulls for Tritrichomonas} foetus

\section{Collection}

Preputial washes were collected from bulls at an organized semen stations. The samples were collected from total of 444 bulls. Out of which 225 samples were collected from North India zone and 219 samples were collected from east and west zones of Tamil Nadu state. Sterile insemination pipette was gently inserted to the full length of preputial cavity and thoroughly massaged with other hand, forcing the pipette to scrap the epithelial cells of smegma/prepuce.

The accumulated fluid was collected into syringe and inoculated into InPouch TF kit (BioMed, USA; Cat No: 11-1010; LOT No: 4SA067). Approximately $200 \mu \mathrm{l}$ sample was used for the inoculation.

\section{Tritrichomonas foetus Culture}

Samples were inoculated in InPouch TF kits and incubated at $35^{\circ} \mathrm{C}-37^{\circ} \mathrm{C}$ for 7 days. The pouches were observed every day under compound microscope for the presence of the organism. Pure culture of T.foetus (Riedmuller) Wenrich and Emerson $\left(\mathrm{ATCC}^{\circledR} 30003^{\mathrm{TM}}\right.$ ) maintaining at our facility was used as positive control.

\section{DNA extraction}

After 7 days of incubation, DNA was extracted from all 444 samples. Total media from InPouch TF kit was transferred into $15 \mathrm{ml}$ tubes and pelleted at 4000 RPM for $5 \mathrm{~min}$. Total DNA was extracted from the pellet using DNAzol. Tritrichomonas foetus (Riedmuller) Wenrich and Emerson $\left(\mathrm{ATCC}^{\circledR} 30003^{\mathrm{TM}}\right.$ ) was used as positive control for DNA extraction and PCR.

\section{Polymerase Chain Reaction}

A Polymerase Chain Reaction was performed using three different sets of primers that are specific to trichomonads and Tritrichomonas foetus $(9,11)$. The PCR reaction was performed by adding $2 \mathrm{X}$ Red Amplicon master mixture, 4.0 p.moles specific primers, in a final reaction volume of $10 \mu 1$.

The PCR was performed with Initial denaturation at $95^{\circ} \mathrm{C}$ for $10 \mathrm{~min} ; 35$ cycles of denaturation at $94^{\circ} \mathrm{C}$ for 30 seconds, annealing at $60^{\circ} \mathrm{C}$ for 40 seconds and Extension at $70^{\circ} \mathrm{C}$ for $1 \mathrm{~min}$; Final extension at $70^{\circ} \mathrm{C}$ for $10 \mathrm{mins}$. PCR thermal cycling condition remains same for all three sets of primers. Sequences of primers are given in the Table-1.

\section{DNA extraction and Polymerase Chain Reaction}

Total genomic DNA was extracted from all 444 samples, after incubating seven days in InPouch TF kit (BIOMED, USA). A polymerase chain reaction was performed with Tritrichomonas foetus specific primers for the identification of organism.

The details of isolates of trichomonadid protozoa were given in the table-2. DNA extracted from pure culture of Tritrichomonas foetus (Riedmuller) Wenrich and Emerson $\left(\mathrm{ATCC}^{\circledR} 30003^{\mathrm{TM}}\right.$ ) was kept as positive control for the comparison. It was observed that DNA extracted from reference culture was amplified and showed specific band with all three sets of primers. 


\section{Results and Discussion}

\section{Morphology of T.foetus}

Tritrichomonas foetus (Riedmuller) Wenrich and Emerson $\left(\mathrm{ATCC}^{\circledR} 30003^{\mathrm{TM}}\right.$ ), strain BP-4: Beltsville from American Culture Collection (ATCC) was used to study the growth kinetics and analytical sensitivity of the detection methods.

The organism was highly motile with three anterior and one posterior flagella with undulating membrane and it was clearly visible under compound microscope. The movement was forward-jerky and flagella was clearly visible in 40X magnification. Both In pouch TF kit (Biomed, USA) and In house Diamonds modified TF media were equally supporting the growth of the organism (Fig. $1 \& 2)$.

\section{Cell count}

The organism mixed in 50\% (V/V) PBS $(\mathrm{pH}$ 8.0) were not so motile but was found alive. The organisms were counted under this condition. The cells in $25 \%$ of PBS were actively moving and could not be counted.

Cells were completely lysed in other two combinations $75 \%$ and $100 \%$ PBS (pH 8.0) probably due to high osmotic pressure.

\section{Growth curve experiment}

Total of $3 \times 10^{6}$ cells were inoculated into fresh ATCC InPouch media $(9.0 \mathrm{ml})$ and incubated at $35^{\circ} \mathrm{C}$. Cell count and OD@600 were measured at 18, 24, 40, $48 \mathrm{Hrs}$ post inoculation. The experiment was repeated for three times. It was observed that the cell count was reaching up to maximum of $6.9 \times 10^{6}$ cells $/ \mathrm{ml}$ (Total- 62.1 million cells in 9ml) in $24 \mathrm{hrs}$ and attaining to decline condition in later hours.
Analytical sensitivity of culture method to detect Tritrichomonas foetus

A total of $3 \times 10^{6}$ cells $(0.9 \mathrm{ml})$ were inoculated into $9 \mathrm{ml}$ of TF media as neat and serially diluted till $10^{-11}$ dilutions. The tubes were incubated at $35^{\circ} \mathrm{C}-37^{\circ} \mathrm{C}$ for 7 days and monitored for the growth of the organism. Any estimate of the diagnostic sensitivity and specificity of the culture and identification test will be dependent on the efficacy of the sample collection, handling and processing and also the quality of the culture medium. In bulls the sensitivity of the InPouch TF kit has been estimated to be $92 \%$ Confidence Interval, $84-96 \%)(7,8)$.

\section{PCR sensitivity}

The total genomic DNA was extracted from all dilutions $\left(10^{6}\right.$ cells to $10^{1}$ cells $)$ and a PCR reaction was performed with $\mathrm{TF}$ specific primers. It was observed that all 3 sets of primers were able to amplify the DNA up to single cell dilution. The PCR is highly sensitive in detecting the organism.

Commercially available tests such as the InPouch TF test represent a useful primary diagnostic tool, and the test can be performed relatively easily. Nevertheless, not all isolates exhibit the same growth kinetics, and the actual identification of the parasite thus becomes very difficult when only a few organisms can be seen in the culture medium and when these organisms, for any reason, do not propagate as expected.

As little as $0.03 \mathrm{pg}$ of purified $T$. foetus DNA could be detected with a high degree of sensitivity by our test; thus, we were able to detect as little as a single parasite per PCR in repeated experiments. Consequently, by using in vitro-propagated material as a sample, the combined sensitivity of the tests becomes extremely high. 
Screening the bulls for Tritrichomonas foetus

\section{Collection and culturing}

Preputial washes were collected from 444 bulls at semen station. The samples were inoculated into Inpouch TF-kit and incubated at $35-37^{\circ} \mathrm{C}$ for 7 days. The pouches were daily monitored under microscope for the growth of the organism for complete 7days and we could not find any live organism from the samples. But with this we cannot conclude that the bulls are free of Tritrichomonas foetus, because the organism might have been dead before collection or at the time of collection. To rule out this we have standardized Polymerase Chain Reaction based method for the identification of presence of T.foetus.

The prevalence of Bovine Trichomonosis in India was not studied properly yet, but still it is suspected that some early abortion reports are due to Tritrichomonas foetus.

The demand for semen doses for artificial insemination has been growing in the country and it is projected that entire semen stations in our country has to produce 140 million doses by the end of 2021-22.

Considering the need for expanding semen production, the existing semen stations are planning to expand and modernize their facility to produce high quality semen.

As per minimum standard protocols for the production of bull semen, it is most important that the bulls used in Artificial Insemination program has to be free of diseases like Foot and Mouth disease, Brucellosis, Tuberculosis, Johne's disease, Trichomonosis, Campylobacteriosis, and Infectious bovine rhinotracheitis (1). The diseased animal should either be culled or removed from herd. Culling of infected bulls is not recommended due to scocio-economic reasons in developing countries. Moreover rearing of animal is costly affair and precious. So, it is important to increase the sensitivity of diagnosing the disease. Presently, as per OIE recommendation Trichomonosis is diagnosed by agent identification and TF Inpouch (Biomed, USA) media or Diamonds modified media is best suitable for the growth of the organism (13).

Even though many laboratories are following OIE recommended procedure for screening, but still problems persist in identifying the organism accurately. To address such troubles and to improve the methodology to identify the organism here, we tried to improve the sensitivity of identifying the organism by TF Inpouch and Polymerase Chain Reaction (PCR) methods.

First time in India we studied the growth conditions, growth sensitivity, corresponding PCR sensitivity of Tritrichomonas foetus (Riedmuller) Wenrich and Emerson $\left(\right.$ ATCC $^{\circledR} 30003^{\mathrm{TM}}$ ) pure culture from ATCC. Further we applied the protocol to screen 444 bulls from Indian govt. authorized semen collection station. We believe our study has explored certain facts that are useful in identifying the organism accurately. Initially we find difficulty in counting the moving organism under microscope. The study conducted by Sarah et al., (2003) has shown that Tritrichomonas foetus to undergo a regulatory volume increase (RVI) when it was subjected to hyper osmotic challenge (3). Based on her work, we thought it is logical to arrest the movement by creating or altering some environmental change. Out of four combinations, 50\% PBS (V/V) (pH-8.0) was observed to be the best for counting. At slightly alkaline and hypotonic condition, the cells are at stress and could not able to move fast. So at this condition we found it is easier to count the cells. 
Table.1 Primer sequences

\begin{tabular}{|c|c|}
\hline Primer & Sequence $\mathbf{( 5}^{\prime}$ to $\mathbf{3}^{\prime}$ ) \\
\hline TFR3 & CGGGTCTTCCTATATGAGACAGAACC \\
\hline TFR4 & CCTGCCGTTGGATCAGTTTCGTTAA \\
\hline TFR3pK & CGGGTCTTCCTATATGAGACAGAACCGGAGCTGAATG \\
\hline TFR4pK & CCTGCCGTTGGATCAGTTTCGTTAAGGGATTTTGGT \\
\hline TFR8-Bio & Biotin-CCGTTTTAGCTTGCTAGAACAC \\
\hline
\end{tabular}

Table.2 Documentation for isolates of trichomonadid protozoa

\begin{tabular}{|c|c|c|c|}
\hline Isolate no. & Species & ATCC strain no. & Strain, origin \\
\hline 1 & Tritrichomonas foetus & & Reference, Switzerland \\
\hline 2 & Tritrichomonas foetus & 30003 & BP-4, United States \\
\hline 3 & Tritrichomonas foetus & 30166 & Belfast, Ireland \\
\hline 4 & Tritrichomonas foetus & 30231 & DK-2, United States \\
\hline 5 & Tritrichomonas foetus & 30232 & UT, United States \\
\hline 6 & Tritrichomonas foetus & 30924 & KV-1, Czech Republic \\
\hline 7 & Tritrichomonas foetus & 50151 & KV1/M-100, Austria \\
\hline 8 & Tritrichomonas foetus & 50152 & KV1-1MR-100, Czech Republic \\
\hline 9 & Tritrichomonas suis & 30167 & 1/N, United States \\
\hline 10 & Tritrichomonas suis & 30168 & 11/S, United States \\
\hline 11 & Tritrichomonas suis & 30169 & C19F, United States \\
\hline 12 & Tritrichomonas mobilensis & 50116 & USA:M776, Bolivia \\
\hline 13 & Tritrichomonas gallinarum & 30097 & TP-79, United States \\
\hline 14 & Pentatrichomonas hominis & 30098 & R51, United States \\
\hline 15 & Trichomonas vaginalis & 30240 & JH37A-2, United States \\
\hline 16 & Trichomonas vaginalis & 30241 & JH37A-4, United States \\
\hline 17 & Trichomonas vaginalis & & Human isolate, Switzerland \\
\hline 18 & Trichomonas gallinae & 30230 & TG \\
\hline 19 & Trichomonas tenax & 30207 & Hs-4:NIH \\
\hline
\end{tabular}

Table.3 Collection of preputial washings from different parts of India

\begin{tabular}{|c|c|}
\hline Area of collection & No. of samples \\
\hline North India & 225 \\
\hline TN East zone & 94 \\
\hline TN West zone & 125 \\
\hline
\end{tabular}

Table.4 Observation chart for Trichomonosis in bovine

\begin{tabular}{|l|l|l|l|l|l|l|l|}
\hline Sample ID. & Day 1 & Day 2 & Day 3 & Day 4 & Day 5 & Day 6 & Day 7 \\
\hline $\begin{array}{l}\text { TRPVB/TRI/0001- } \\
\text { 0444 }\end{array}$ & N & N & N & N & N & N & N \\
\hline
\end{tabular}


Fig.1 Showing the growth of Tritrichomonas foetus (Riedmuller) Wenrich and Emerson $\left(\right.$ ATCC $^{\circledR} 30003^{\mathrm{TM}}$ ), strain BP-4: Beltsville from American Culture Collection (ATCC) in A. InPouch Diamonds modified TF kit, B.

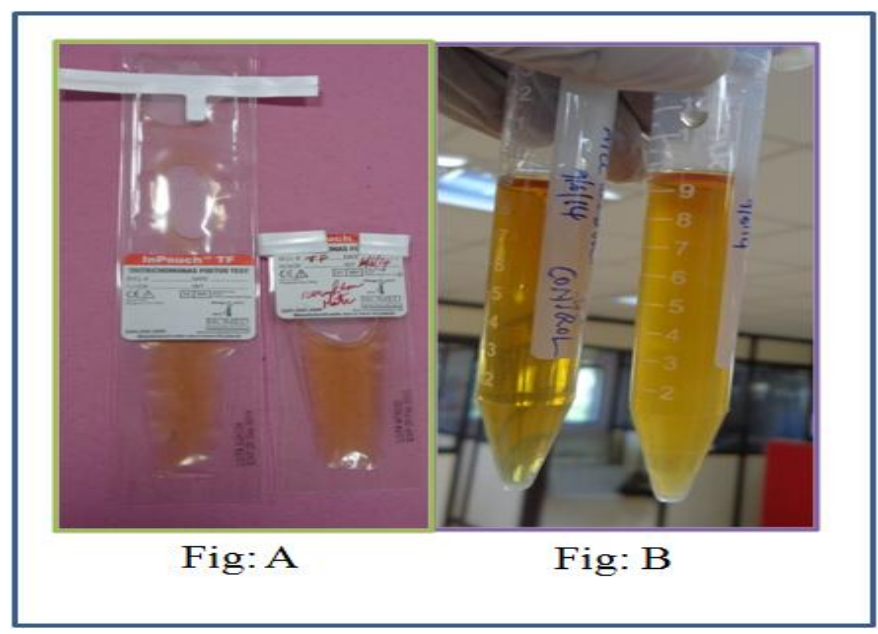

Fig.2 Microscopic observation of Tritrichomonas foetus (Riedmuller) Wenrich and Emerson $\left(\right.$ ATCC $^{\circledR} 30003^{\mathrm{TM}}$ ), strain BP-4: Beltsville from American Culture Collection (ATCC).Panel A -- 10X magnification; panel B ----- 40X magnification.

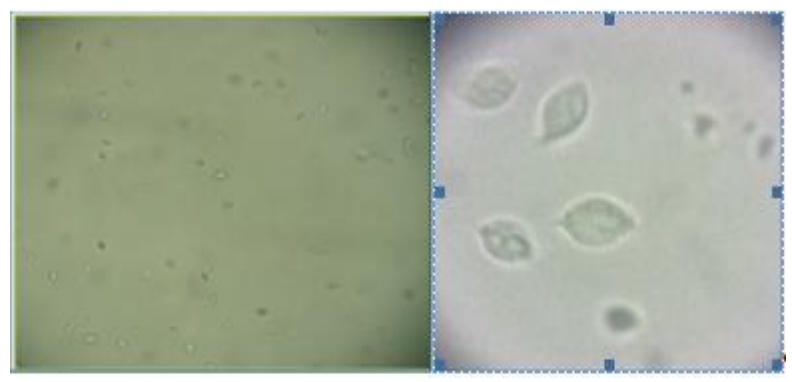

Fig.3 Graph showing the cell count of Tritrichomonas foetus at different time intervals.

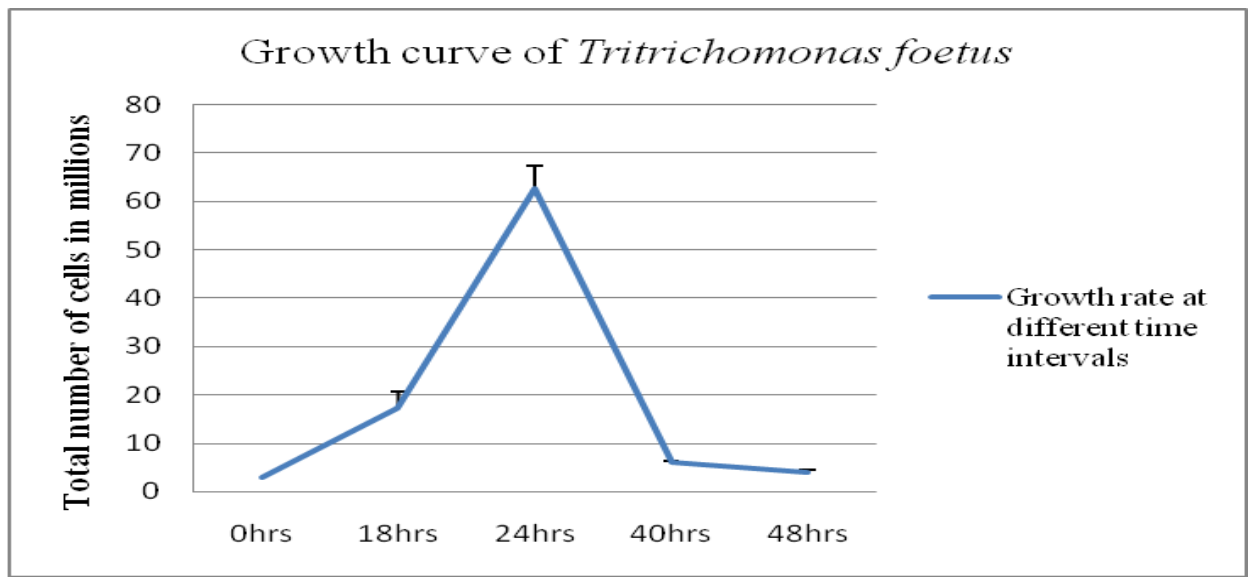


Fig.4A\&B 1.5\% Agarose gels showing the results of amplification of 99 samples with amplification of Tritrichomonas foetus (Riedmuller) Wenrich and Emerson (ATCC ${ }^{\circledR} 30003^{\mathrm{TM}}$ ) DNA from $10^{6}-10^{-1}$ cells with ITS primers with positive control on $11^{\text {th }}$ lane.

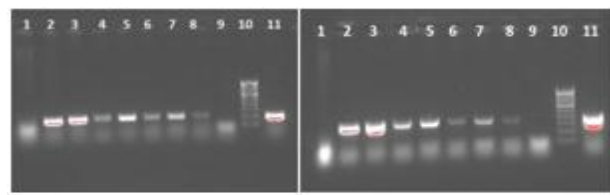

Fig 4A

Fig4B

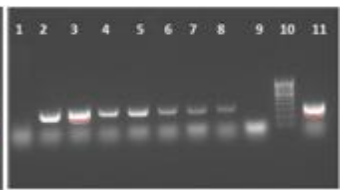

Fig4C

4A- 208bp Showing amplification ITS and TFR1, R2 primers 4B-342bp and TFR1R2 primers 4C-350bp. $1^{\text {st }}$ lane contains -ve reaction.

Fig.5 1.5\% Agarose gels showing the results of amplification of 115 samples with

Tritrichomonas foetus TFR1 \&TFR2 primers (5.8s ribosomal RNA specific primers). Tritrichomonas foetus (Riedmuller) Wenrich and Emerson $\left(\mathrm{ATCC}^{\circledR} 30003^{\mathrm{TM}}\right.$ ) was kept as positive control. $1 \mathrm{~KB}$ marker was used and $-\mathrm{VE}$ is reaction negative.
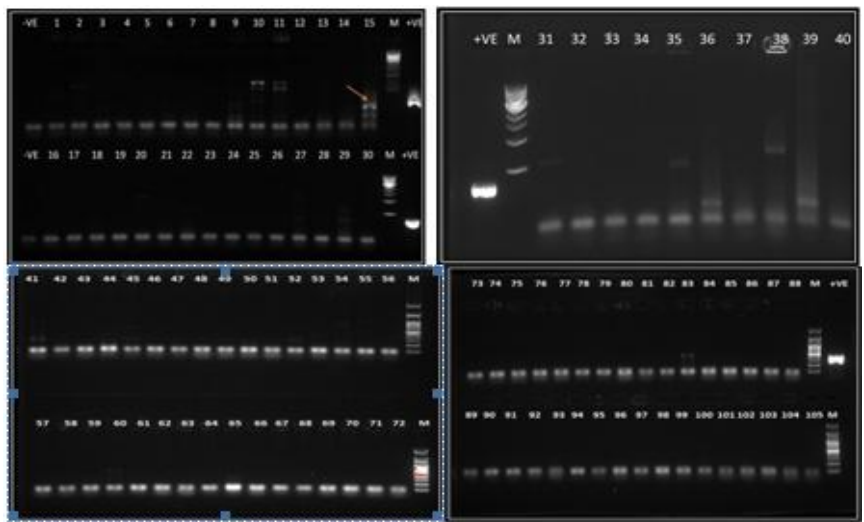

Fig.6 1.5\% Agarose gels showing the results of amplification of 115 samples with Tritrichomonas foetus TFR3 \&TFR4 primers (5.8s ribosomal RNA specific primers). Tritrichomonas foetus (Riedmuller) Wenrich and Emerson $\left(\mathrm{ATCC}^{\circledR} 30003^{\mathrm{TM}}\right.$ ) was kept as positive control. 100bp marker was used and -ve is reaction negative.
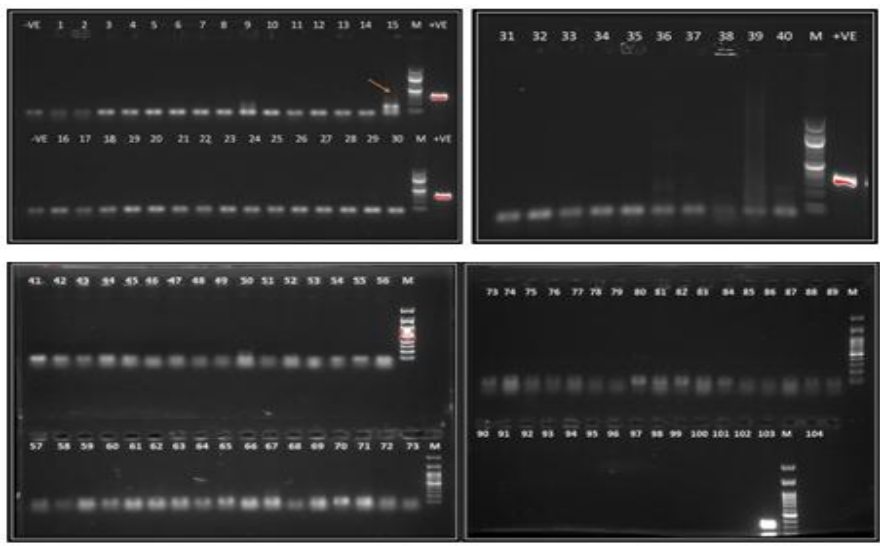
Fig.7 1.5\% Agarose gels showing the results of amplification of 115 samples with Tritrichomonas foetus ITS (Inter transcription spacer) primers. Tritrichomonas foetus (Riedmuller) Wenrich and Emerson $\left(\mathrm{ATCC}^{\circledR} 30003^{\mathrm{TM}}\right.$ ) was kept as positive control. $1 \mathrm{~KB}$ marker was used and -ve is reaction negative.
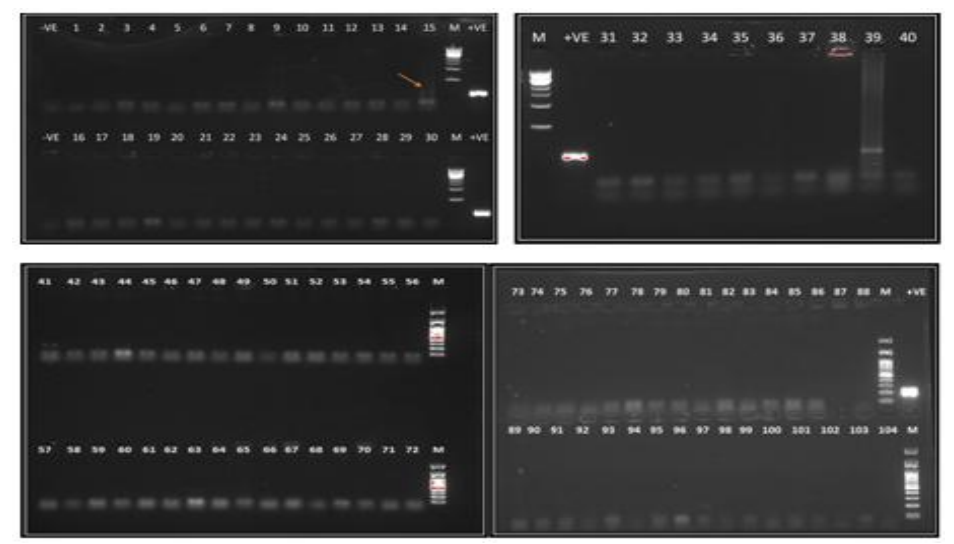

The turbidity of organism was estimated at $\mathrm{OD}_{600}$ and it was observed that there is gradual increase in turbidity for 18, 24, 40, 48 Hrs. The $\mathrm{OD}_{600}$ is reached maximum of 0.61 (Fig. $3)$. The $\mathrm{OD}_{600}$ at $24 \mathrm{hrs}$ is 0.4 . It was observed, after $24 \mathrm{hrs}$ the cells were reached to decline phase and the viable count were reduced to $4 \mathrm{X} 10^{6}$ cells $/ \mathrm{ml}$ by $48 \mathrm{hrs}$. It was also noted that $\mathrm{OD}_{600}$ remained same at 0.61 . One reason this may be is due to cell debris. At certain stage, even though the viable cells started coming to decline phase, cell debris remains same and due to which the $\mathrm{OD}_{600}$ continued to be at 0.61 . The increase in $\mathrm{OD}_{600}$ after $24 \mathrm{hrs}$ should not be taken into consideration and we have concluded that for Tritrichomonas foetus in $\mathrm{TF}$ media, when $\mathrm{OD}_{600}$ reaches to 0.4 the cell count is approximately $6.9 \times 10^{6}$ cells $/ \mathrm{ml}$. At this point $400 \mu 1$ of inoculums would contain a total of $3 \times 10^{6}$ cells and it reaches to $6.9 \times 10^{6}$ cells/ml in 24Hrs (Fig. 4-7).

It was also observed both Inpouch as well as Diamond's media are supporting adequately the growth of the organism. The presence of even a single organism is reaching maximum $\mathrm{OD}_{600}$ to 0.4 within 7 days. The PCR sensitivity was observed to be very high in detecting the organism. DNA was amplified with all 3 sets of primers and it was able to amplify even at 0.1 dilutions. After studying carefully the growth conditions, growth sensitivity, and PCR sensitivity, we have optimized method and sampled 444 bulls from authorized semen station. We have collected Preputial wash, inoculated into Inpouch TF kit and incubated at $35-37^{\circ} \mathrm{C}$ for seven days. DNA was extracted and verified for any amplification. The PCR method was performed for the detection of Tritrichomonas foetus genome in 444 samples. At each step, pure culture was used as positive control for comparison. To the best of our observation and repeated PCR experiments we could not able to find any traces of genome from 444 samples. We have concluded that the bulls were free of Tritrichomonas foetus. The purpose of the study and our long term aim is to examine the prevalence of Bovine Trichomonosis in India which intern may help several semen stations to know the Trichomonosis status. After collection, it was observed around $2-3 \%$ of Inpouch TF kit is cross contaminated with some gram negative bacteria and candids. The government farms are maintained at high standards, which may be one reason for negative results. Female is proper source of organism and most of the bulls are never mated with the female. These 
bulls are used for the collection of semen for Artificial Insemination. This may be one more strong reason for obtaining negative results in identifying Tritrichomonas foetus. Targeting diseased bulls, aborted cases, freelancer bulls, bulls at a slaughter house and unorganized farms sounds logical to obtain positive results.

\section{References}

Annual Report, Department of Animal Husbandry, Dairying and Fisheries, Ministry of Agriculture, Government of India, New Delhi, 2011-12.

Goodger W.M, S.Z. Skirrow. Epidemiologic and economic analyses of an unusually long epizootic of Trichomonosis in a large California dairy herd. Journal of the American Veterinary Medical Association 1986; 189: 772-776

Gunasilan., Sarah L. Maroulis, Philip J. Schofield, and Michael R. Edwards. (2003) Osmo-regulation in the Parasitic Protozoan Tritrichomonas foetus Applied and Environmental Microbiology, 4527-4533.

Mc causland I.P., K. J. Slee and F. S. Hirt. (2008). Mycotic abortion in cattle. Aust. Vet. J. 6 (5): 129-132.

Mc Cool C.J, M.P. Townsend, S.G. Wolfe, M.A. Simpson, T.C. Olm, G.A. Jayawardhana and Carney, J.V. Prevalence of bovine venereal disease in the Victoria River District of the Northern Territory: likely economic effects and practicable control measures. Australian Veterinary Journal 1988; 65: 153-156

OIE manual., (2012) Diagnostic Tests and Vaccines for Terrestrial Animals Seventh Edition, 2012.
Pareek, P. K.; S. S. Sharma, B. L. Bishnoi, A. K. Gupta, Trichomonosis in cattle in northwest Rajesthan Indian Journal of Animal Reproduction 199415 (1) 27-28.

Parker S., J.R.Campbell, C.Ribble and A.A. Gajadhar (1999). Comparison of two sampling tools for diagnosis of Tritrichomonas foetus in bulls and clinical interpretation of culture results. J. Am. Vet. Med. Assoc., 215, 231-235.

Parker S., J.Campbell, C.Ribble, A.Gajadhar 2003b; Sample collection factors affect the sensitivity of the diagnostic test for Tritrichomonas foetus in bulls. Can J Vet Res 67:138-141

Rae DO. Impact of Trichomonosis on the cow-calf producer's profitability. Journal of the American Veterinary Medical Association 1989; 194: 771 775

Sarfaraz Nawaz Sanjrani, Khuda Bux Mirbahar, Hidayatullah Soomro and Hakim Ali Sahito (2013). Prevalence of abortion in Kundhi buffalo in district Hyderabad, Sindh - Pakistan. Herald Journal of Agriculture and Food Science Research Vol. 2 (1), pp. $070-077$

Skirrow, S. Z., and R. H. BonDurant. 1988. Bovine Trichomonosis. Vet. Bull. 58:591-603.

Yao C (2013) Diagnosis of Tritrichomonas foetus-infected bulls, an ultimate approach to eradicate bovine Trichomonosis in US cattle $\mathbf{J}$ Med Microbiol 62:1-9.

\section{How to cite this article:}

Ananthakumar, K. V., K. Sathish, G. Dhinakar Raj, M. Raman, Amir Kanji and Azhahianambi, P. 2021. Screening for Bovine Trichomonosis at Organized Farms using Inpouch TF Kit. Int.J.Curr.Microbiol.App.Sci. 10(02): 1209-1218. doi: https://doi.org/10.20546/ijcmas.2021.1002.142 